\title{
Core-shell Fluorine-silicon Modified Polyacrylic Coating for Corrosion Protection of 304 Stainless Steel Substrate
}

\author{
Xia Wang*, Linglong Xu, Hui Wang, Xiong Li, Qiao Zhang,Yue Gu \\ School of New Energy and Materials, Southwest Petroleum University, Chengdu, 610500, China \\ "E-mail: swpi_wx@126.com (Xia Wang), 1067206436@qq.com (Linglong Xu)
}

doi: $10.20964 / 2021.01 .75$

Received: 9 October 2020 / Accepted: 15 November 2020 / Published: 30 November 2020

\begin{abstract}
A serious of core-shell fluorine-silicon modified polyacrylic emulsion had been prepared by seeded emulsion polymerization. Methylmethacrylate (MMA), butyl acrylate (BA) and acrylic acid (AA) were used as the monomers of polyacrylic core. And the shell of the emulsion was modified by polyacrylic with dodecafluoroheptyl methacrylate (DFMA), vinyl triethoxysilane (VTEO) and tetraethyl orthosilicate (TEOS). The completed of reaction was proved by fourier transform infrared spectroscopies (FT-IR). TEM analysis indicated core-shell structure of the hybrid particles. The surface analysis indicated that the excessive addition of VTEO-TEOS had a negative effect for the film. Electrochemical Impedance Spectroscopy (EIS) indicated that the anti-corrosion of the film went up first and then down with the increase of VTEO-TEOS content. The best anti-corrosion content of VTEO-TEOS was $1.0 \%(\mathrm{~F}-1.0 \mathrm{Si})$. In this, the corrosion current density of the coating had reached $3.7 \times 10^{-8} \mathrm{~A} \cdot \mathrm{cm}^{-2}$, the efficiency of anti-corrosion was $99.53 \%$, the water contact angle was $99^{\circ}$ and the thermal decomposition temperature was $298^{\circ} \mathrm{C}$. Two glass transition temperature indicated that the emulsion was the structure of two phases with different properties. The high-efficiency anti-corrosion time of film within $300 \mathrm{~h}$ was showed with immersion experiment.
\end{abstract}

Keywords: Core-shell; Anti-corrosion; Stainless steel;Fluorine-silicon;Water diffusion

\section{$\underline{\text { FULL TEXT }}$}

(C) 2021 The Authors. Published by ESG (www.electrochemsci.org). This article is an open access article distributed under the terms and conditions of the Creative Commons Attribution license (http://creativecommons.org/licenses/by/4.0/). 